\title{
Assessing the Knowledge, Attitude, and Practices of Cigarette Smokers and Use of Alternative Nicotine Delivery Systems in Pakistan: A Cross-Sectional Study
}

\author{
Abdul Hameed $(D)$ and Daud Malik \\ Alternative Research Initiative (Pvt.) Ltd., Islamabad, Pakistan \\ Correspondence should be addressed to Abdul Hameed; hameedleghari@gmail.com
}

Received 15 February 2021; Revised 27 April 2021; Accepted 8 September 2021; Published 24 September 2021

Academic Editor: Sylvester C. Chima

Copyright (c) 2021 Abdul Hameed and Daud Malik. This is an open access article distributed under the Creative Commons Attribution License, which permits unrestricted use, distribution, and reproduction in any medium, provided the original work is properly cited.

\begin{abstract}
Background. This research has been conducted to assess smokers' knowledge and behavior vis-à-vis combustible smoking cessation, prevalence, and risk, and the use of alternative nicotine delivery systems to quit smoking. Methods. A mixed-method approach utilizing cross section primary survey data and comprising descriptive and s-KAP index analysis has been adopted to ascertain the relationship between dependent and independent s-KAP variables; the principal component analysis methodology has been used to determine the use of alternative nicotine delivery systems. Results. Most of the smokers were aged between 15 and 35 years. A predominant $69.8 \%$ of the smokers came from middle-class background. Moreover, $71.3 \%$ were unaware of any alternative Tobacco Harm Reduction product. A majority of the respondents (68.2\%) were keen to quit smoking. However, when asked why they had not succeeded, $52.9 \%$ reported addiction to nicotine as the main impediment. In Pakistan, lack of smoking cessation services is the weak link in the fight against the tobacco epidemic. Smokers are generally unaware of the Tobacco Harm Reduction products available in Pakistan; moreover, only $10.9 \%$ of the respondents were willing to spend more than Rs. 4000 per month on Tobacco Harm Reduction products. The average s-KAP score for young adults below the age of 20 was much lower than the national average but improved with the level of education. Interestingly, the score of smokers who had ever tried to quit smoking was slightly higher than that of those who had never tried to quit. Conclusion. There is intent to quit combustible smoking but the policy and infrastructure necessary for successful quitting are missing. Pakistan needs to concentrate on two fronts: a large scale awareness campaign against the use and harms of combustible smoking and simultaneously providing affordable and accessible smoking services across the country. Pakistan should look at the use and regulation of safer nicotine products in the UK. The country should carefully weigh the options of ensuring how to incorporate the use of safer nicotine delivery systems in its tobacco control efforts.
\end{abstract}

\section{Introduction}

Tobacco consumption is a predominant cause of preventable deaths worldwide. There are 1.3 billion tobacco smokers living in low- and middle-income countries. Every year, more than 8 million people die from tobacco use; of these, more than 7 million die directly from tobacco while 1.2 million die from Secondhand Smoke (SHS). Even though all forms of tobacco are life-threatening, smoking cigarettes is the most prevalent in the world [1]. According to the World Health Organization (WHO), the consumption of cigarettes has declined in the Americas (AMRO), the European Region (EURO), and the Western Pacific Region (WPRO). However, between 1999 and 2016, cigarette consumption increased in countries such as China (0.71 trillion), as well as the African Region (AFRO, 0.03 trillion), the Eastern Mediterranean Region (EMRO, 0.09 trillion), and the South-East Asia Region (SEARO, 0.23 trillion). According to age-standardized methods, the prevalence of daily smoking in males $(25 \%)$ and females (42\%) declined between 1980 and 2012, but the total number of daily smokers grew by $41 \%$ in males and $7 \%$ in females due to a rise in population growth $[2,3]$. 
The important question is how have these countries been able to minimize smoking prevalence? They have done so primarily due to public recognition of the value of health and wellbeing, and implementation of prevention initiatives including price, regulation, and taxation [4]. The burden of tobacco use has risen the most in China and Southeast Asia [5]. Pakistan, India, Bangladesh, and Sri Lanka are among vulnerable countries in Asia, with a substantial number of people consuming tobacco and cigarettes [6]. Compared to India and Sri Lanka, Pakistan and Bangladesh are among countries where a significant number of adults aged 15-65+ years use tobacco smoking [7].

In Pakistan, one in every five adults uses some form of tobacco (Global Adult Tobacco Survey [8]). This translates into nearly 25 million consumers of tobacco with 160,189 deaths, more in males $(120,240)$ than in females $(39,949)$ [9]. Several tobaccos, waterpipes, "shisha," "pan," "gutka," and "niswar" are consumed [10]. The annual consumption of combustible cigarettes is around 86 billion sticks [11]. This includes both locally produced registered and illicit brands. Although Pakistan has been taking measures to contain the use of tobacco ever since 2004 when it ratified the WHO Framework Convention on Tobacco Control (FCTC), the country is yet to formulate a national policy on tobacco controls.

Smoking cessation is one of the weakest links in the fight against tobacco use in Pakistan, where the success rate of quitting is less than 3\% [12]. According to the WHO cessation index, Pakistan offers Nicotine Replacement Therapy (NRT) and/or some cessation services with at least one cost covered (https://tobaccoatlas.org/topic/quitting/). As information about smoking cessation services is not widely disseminated, even the young, educated well-to-do smokers who want to quit do not know about such services [12]. Almost half of the quit attempts are unaided in Pakistan due to lack of knowledge about smoking cessation services [8]. Pakistan, after India, is one of the top tobacco producing countries in South Asia. However, the share of tobacco farming in the overall irrigated land of Pakistan is $0.25 \%$, with 75,000 growers, most of them in Khyber Pakhtunkhwa. The overall tobacco produce is $0.42 \%$ of the total farming produce in Pakistan [9].

Even though a nascent phenomenon, Pakistan has witnessed a steady increase in the use of Tobacco Harm Reduction (THR) products such as e-cigarettes and nicotine pouches over the last five years [13]. Variously called Electronic Nicotine Delivery Systems (ENDS) or Safer Nicotine Delivery Systems (SNDS), these HRPs are used in regulatory vacuum. However, e-cigarettes and other HRPs are legally imported as consumer goods, with tax duties imposed on them. Currently, the data on tobacco use in Pakistan are old, if not outdated. Since GATS [8], no new nationwide research has been conducted vis-à-vis tobacco use.

There is an urgent need to gauge the exact situation of tobacco use in Pakistan, ranging from the total number of smokers and young smokers, to SHS and illicit trade, etc.
Although a number of small studies have been conducted on these topics, the need for a fresh perspective can hardly be overemphasized. A review and reevaluation of tobacco-related issues can help determine the kind of interventions that can be made to affect a decline in smoking prevalence by 2030 and meet the target of strengthening "the implementation of the WHO's FCTC in all countries, as appropriate" under the Sustainable Development Goal (SDG) 3. In view of the abovementioned, this research seeks to fill the gap by offering an assessment of the knowledge and behavior of smokers in relation to combustible smoking cessation, prevalence, and risk, and the use of ANDS to quit smoking.

Section 2 of the study addresses the analytical context for s-KAP calculation and data used in the empirical study of s-KAP and its source. The findings of the empirical analysis are discussed in Section 3, while Section 4 focuses on policy implications and conclusion.

\section{Methodological Framework of s-KAP}

Multiple approaches and procedures are available in literature to ascertain cigarette smokers' knowledge, attitude, and practice (s-KAP). Most research studies [14-19] offer a basic descriptive analysis and apply chi-square and $t$-test to assess the relationship between dependent and independent variables. A few studies have used KAP index and logistic regression, while others have employed multivariate analysis [20-22]. For this research, a mixed-method approach comprising descriptive analysis and s-KAP index analysis was adopted to evaluate the relationship between dependent and independent s-KAP variables and the use of ANDS, using STATA (version 15.1). A simple frequency and percentage of data were used for descriptive analyses and the principal component analysis (PCA) methodology was used to construct the s-KAP index by means of KAP indicators, which are a proxy for smokers' behavior. It is commonly used in social science to build scores and reduce the number of variables into simple index scores [23-25]. This approach is used in two distinct ways of covariance and correlation matrix. However, this research employed correlation matrix technique because of different units of variables [26]. The mathematical shape of the PCA is

$$
\begin{aligned}
& P C_{1}=\alpha_{11} Y_{1}+\alpha_{12} Y_{2}+---+\alpha_{1} n Y_{n}, \\
& P C_{1}=\alpha_{21} Y_{1}+\alpha_{22} Y_{2}+---+\alpha_{2} n Y_{n}, \\
& ---------------- \\
& ---------------- \\
& P C_{m}=\alpha_{m 1} Y_{1}+\alpha_{m 2} Y_{2}+---+\alpha_{m} n Y_{n}
\end{aligned}
$$

where

$P C 1, P C 2$ and $P C m$ are principal component equations with $Y n$ different variables and $m n$ equation weights. Formally, the linear combination of the index for smokeri is calculated, based on the following equation: 


$$
\begin{aligned}
Y_{i}= & \alpha_{1}\left(\frac{X_{1}-\bar{X}_{1}}{S_{1}}\right)+\alpha_{2}\left(\frac{X_{2}+\bar{X}_{2}}{S_{2}}\right)+\cdots \cdots \cdots \cdots \\
& +\alpha_{K}\left(\frac{X_{K}+\bar{X}_{K}}{S_{K}}\right)
\end{aligned}
$$

where $Y i$ is the index, $X k$ is the mean, $S K$ is the standard deviation, and $\alpha_{k}$ are the weights. Based on the PCA calculation, the first principal component (PC1) yields the highest weights between positive and negative values. For translation to a normalized value, the mean value of the score is subtracted from the real value of the respective indicator and divided by the standard deviation. In addition, these uniform scores are multiplied by $\mathrm{PC} 1$ in order to achieve scores of each dimension. The sum of each dimension of the score results from the final index at the respondent level. Finally, the respondent level index contrasts with cross-reference categories of variables.

2.1. Description of s-KAP Variables. The selection of s-KAP variables (see Table 1) was based on literature review conducted in line with WHO-recommended core questions for assessing smoking status, and GATS. These s-KAP variables reflect respondent characteristics such as gender, age, education, classification of residential area, knowledge related to use of cigarettes and safer ANDS, attitude regarding social acceptance and SHS, and practice.

2.2. Data and Sources. The study used cross-sectional survey data from 13 large district cities of all provinces and territories of Pakistan. According to the study objectives and budget constraints, three districts each of Punjab and Sindh, two districts each of Khyber Pakhtunkhwa (KP) and Balochistan, one district each of Azad Jammu and Kashmir (AJK) and Gilgit-Baltistan, and Islamabad Capital Territory were selected for this study. A semi-structural questionnaire was developed from a rigorous literature review. The questionnaire focused on the characteristics, knowledge, attitude, and practice of smokers and the use of ANDS and was exercised via telephonic interviews. A sample of 650 cigarette smokers was randomly chosen at the study representation level, based on Cochran's sample size formula, using $95 \%$ confidence level, a $5 \%$ margin of error, and a $7 \%$ adjustment for nonresponse. The following sample size calculation was used for accuracy:

$$
s s=\frac{Z^{2} *(p) *(1-p)}{c^{2}},
$$

where $Z$ value is e.g., 1.96 for $95 \%$ confidence level, $p$ is the percentage picking a choice, expressed as decimal ( 0.5 used for sample size needed), and $c$ is the confidence interval, expressed as decimal (e.g., $0.07= \pm 7$ ).

An accurate, robust, and statistically representative sample requires a complete and updated sampling frame. Keeping the objectives of the survey in view, a sample of 650 respondents was randomly selected, using preexisting cigarette smoker listing data. Moreover, the distribution of the same sample was carried out at the district level as reflected in Table 2 .

2.3. Selection Procedure. This study has used simple random sampling for the selection of respondents from the preexisting cigarette smokers' listing data. The preexisting cigarette smoker listing was prepared by Pakistan Alliance for Nicotine and Tobacco Harm Reduction (PANTHR). One of its objectives was to talk with and listen to smokers in terms of their efforts/struggles to quit smoking and what kind of help they need to give up this habit. Currently, PANTHR has more than 12000 potential smokers' members from the randomly selected clusters in 27 large district cities across Pakistan. For this particular study, we selected required number of smokers from the 13 selected districts. Because of Covid-19 pandemic and budget constraints, we opted for 50 random smokers per district sample for the telephonic survey.

The following criteria were adopted for listing:

(i) 18 years of age and above

(ii) Adult smoker residing in the respective area

(iii) Willingness to share smoking experience

2.4. Ethical Consideration. The study was approved by the ARI internal Ethics and Technical Committee to ensure research quality and ethics. A verbal consent of the participants was obtained before starting the interview. Furthermore, confidentiality and anonymity of the respondents were ensured.

\section{Empirical Results}

3.1. Characteristics of Smokers. As many as 648 of 650 respondents across various provinces and regions of Pakistan, as reflected in Table 2, were interviewed for the study. As seen in Table 3, all smokers were males. According to the study findings, most of the respondents were aged between 15 and 35 years with an average age of $28.5 \pm 8.2$ years. Most of the respondents were educated; one-fifth had done their matriculation $\left(10^{\text {th }}\right.$ grade $)$ while one-fourth had passed the intermediate level $\left(12^{\text {th }}\right.$ grade). Similarly, one-fifth of the respondents were graduates and $12 \%$ had completed their master's and MPhil/Ph.D. education. A predominant $69.8 \%$ of the smokers came from middle-class background, while $19.8 \%$ were poor.

3.2. Smokers' Knowledge. Smokers' knowledge about smoking-related diseases, cessation, and THR products was significantly linked to the government's tobacco control strategy. Health is a major component of human capital, and health spending is closely linked with economic growth $[27,28]$. As reflected in Table 4, a majority of the respondents (72.2\%) knew that smoking causes cancer. When asked which cancers, $37.8 \%$ of the respondents said lung cancer, $35.9 \%$ referred to mouth cancer, and $17.3 \%$ said it causes cancer of the throat. While it is encouraging to know that a 
TABLE 1: s-KAP domains and indicators.

\begin{tabular}{|c|c|}
\hline Domains & Indicators \\
\hline Characteristics & $\begin{array}{c}\text { Gender } \\
\text { Age } \\
\text { Education } \\
\text { Residential area classification }\end{array}$ \\
\hline Knowledge & $\begin{array}{c}\text { Smoking-related illnesses } \\
\text { Smoking cessation services } \\
\text { Banning of cigarette smoking in Pakistan } \\
\text { THR products }\end{array}$ \\
\hline Attitude & $\begin{array}{c}\text { Social acceptance of smokers } \\
\text { Smoking ban at work and in public places } \\
\text { Young people and smoking } \\
\text { SHS smoking } \\
\text { Permission to smoke in home/car }\end{array}$ \\
\hline Practice & $\begin{array}{c}\text { Use of cigarettes } \\
\text { Illnesses faced } \\
\text { Quit smoking attempt(s) made } \\
\text { Reasons for failed quit attempt(s) } \\
\text { Use of THR products } \\
\text { Willingness to use safer ANDS }\end{array}$ \\
\hline
\end{tabular}

TABLE 2: Study sample size.

\begin{tabular}{|c|c|c|c|}
\hline Province/region & District & $\begin{array}{l}\text { Required sample } \\
\text { size }\end{array}$ & $\begin{array}{c}\text { Covered } \\
\text { sample }\end{array}$ \\
\hline ICT & Islamabad & 50 & 47 \\
\hline \multirow{3}{*}{ Punjab } & Lahore & 50 & 49 \\
\hline & Multan & 50 & 50 \\
\hline & Muzaffargarh & 50 & 50 \\
\hline \multirow{3}{*}{ Sindh } & Hyderabad & 50 & 50 \\
\hline & Karachi & 50 & 50 \\
\hline & Nawabshah & 50 & 50 \\
\hline \multirow{2}{*}{$\mathrm{KP}$} & Peshawar & 50 & 50 \\
\hline & Swabi & 50 & 50 \\
\hline \multirow{2}{*}{ Balochistan } & Quetta & 50 & 54 \\
\hline & Qila Abdullah & 50 & 50 \\
\hline AJK & Bagh & 50 & 50 \\
\hline GB & Ghanche & 50 & 48 \\
\hline \multicolumn{2}{|c|}{ Total } & 650 & 648 \\
\hline
\end{tabular}

majority of the respondents were aware of the carcinogenic properties of tobacco smoking, $85 \%$ had no idea about the availability of cessation services in Pakistan; the lack of these services is the weakest link in the fight against the tobacco epidemic. Smokers were also aware of places where smoking is banned. Most of them (29.2\%) said smoking is banned in public places, followed by hospitals $(24.3 \%)$, public transport (18.2\%), and educational institutions (16.1\%).

A majority of the respondents confirmed not getting verified information about the dangers of smoking. Only $28.7 \%$ said they had come across some information about the dangers of smoking in the last 30 days; social media was the primary source of information for $41.4 \%$ of the respondents. Another important source identified by smokers was representatives of a newly launched ANDS product in Pakistan; 27.4\% of the respondents said representatives of the product informed them about the
TABLE 3: Characteristics of smokers.

\begin{tabular}{lcc}
\hline & Percentage & $N=648$ \\
\hline Gender & & \\
Male & 100.0 & 648 \\
\hline Age (years) & 5.6 & 36 \\
16 to 20 & 28.9 & 187 \\
20 to 25 & 32.6 & 211 \\
25 to 30 & 14.2 & 92 \\
30 to 35 & 7.4 & 48 \\
35 to 40 & 5.4 & 35 \\
40 to 45 & 3.1 & 20 \\
45 to 50 & 2.9 & 19 \\
50 and above & & \\
Education & 6.0 & 39 \\
Illiterate & 4.0 & 26 \\
Primary & 8.3 & 54 \\
Middle & 20.7 & 134 \\
Matriculation & 24.2 & 157 \\
Intermediate & 24.9 & 77 \\
Graduation & 11.9 & \\
MA/MPhil/Ph.D. & & 15 \\
Residential area classification & 2.3 & 452 \\
Rich & 8.2 & 128 \\
Upper-middle class & 69.8 & \\
Middle class & 19.8 & \\
Poor & & \\
\hline
\end{tabular}

dangers of smoking. Only $3.8 \%$ and $13.4 \%$ of the respondents saw information about the ill-effects of smoking in the print and electronic media, respectively, in the last 30 days. A majority of the smokers (71.3\%) did not know about the presence of alternative THR products, which are variously called Safer Nicotine Delivery Systems, Electronic Nicotine Delivery Systems, or alternative nicotine delivery systems, commonly referred to as electronic cigarettes (ecigarettes). 
TABLE 4: Smokers' knowledge.

\begin{tabular}{lcc}
\hline \multicolumn{1}{c}{$\%$} & $N=648$ \\
\hline Do you think cigarette smoking can cause cancer(s)? & \\
Yes & 72.2 & 468 \\
No & 27.8 & 180 \\
If yes, what kind of cancers? & & \\
Lungs & 37.8 & 177 \\
Throat & 17.3 & 81 \\
Mouth & 35.9 & 168 \\
Kidney & 1.9 & 9 \\
Stomach & 0.9 & 4 \\
Liver & 4.9 & 23 \\
Blood & 0.9 & 4 \\
Skin & 0.4 & 2
\end{tabular}

Where do you think are smoking cessation services available in Pakistan?

Tobacco cessation centres

Hospitals

Private doctors

Drug control centres

Private organizations

Do not know

Where do you think is cigarette smoking banned in Pakistan?

$\begin{array}{lll}\text { Public places } & 29.2 & 329\end{array}$

Hospitals $\quad 24.3 \quad 273$

Educational institutions $\quad 16.1 \quad 181$

Public transport $\quad 18.2 \quad 205$

Others $12.3 \quad 138$

Do you know or have you ever heard about THR products such as e-cigarettes?

$\begin{array}{lll}\text { Yes } & 25.3 & 164\end{array}$

No $\quad 74.7 \quad 484$

If yes, how did you come to know about these products?

Friends $\quad 51.6 \quad 96$

Vendors $\quad 13.4 \quad 25$

$\begin{array}{lll}\text { Newspapers } & 4.3 & 8\end{array}$

$\begin{array}{lll}\text { Internet } & 18.8 & 35\end{array}$

Saw others vaping and inquired $\quad 7.5 \quad 14$

Others

4.38

In the last 30 days, did you come across any information about the dangers of smoking?

$\begin{array}{lll}\text { Yes } & 28.7 & 186\end{array}$

No $\quad 71.3 \quad 462$

If yes, what was the source?

$\begin{array}{lll}\text { Print media } & 3.8 & 7\end{array}$

Electronic media $\quad 13.4 \quad 25$

$\begin{array}{lll}\text { Social media } & 41.4 & 77\end{array}$

Billboards $\quad 1.1 \quad 2$

Articles $\quad 0.5 \quad 1$

Research papers $\quad 7.0 \quad 13$

ANDS representatives $\quad 27.4 \quad 51$

Family/friends

$5.4 \quad 10$

3.3. Smokers'Attitude. As reflected in Tables 5 and 6, young smokers often associate smoking with glamor. However, $28.6 \%$ of the smokers disagreed with the notion that smoking makes young people feel fit in and cool. As many as $35.2 \%$ of the respondents agreed and $55.3 \%$ strongly agreed for ban on combustible smoking at work and in public places. Although they are themselves currently smoking, $62.7 \%$ of the respondents strongly believed that young people should stay away from the addictive habit, meaning that they understand that combustible smoking is harmful and dangerous and hence do not want young people to become smokers.

Smokers are also aware of the harmful effects of SHS on children and other people around them. A predominant $74.1 \%$ of the respondents said they would not allow anyone to smoke in their car; $70.2 \%$ termed cigarette smoke harmful for others. A majority of the respondents (68.2\%) claimed wanting to quit smoking. However, when asked why they have not been able to quit, $52.9 \%$ reported addiction to nicotine as the key impediment.

3.4. Smokers' Practices. Most of the respondents (60.6\%) said they had been smoking cigarettes for more than three years, followed by $14.5 \%$ and $13 \%$ who had been smoking for the last three and two years, respectively. Similarly, most of them (75.8\%) smoke daily. A little more than $30 \%$ of the respondents smoke 16-20 and more than 20 cigarettes per day. However, one-fourth (23.6\%) smoke 6-10 cigarettes a day (Table 7).

As far as smoking cessation is concerned, $48 \%$ of the respondents had made at least one attempt to quit smoking while $34.1 \%$ had made more than three attempts. Dependence on nicotine (48.3\%) is the major reason for failure to quit smoking, followed by living or working with smokers (15.7\%), and stress and anxiety (13.7\%).

3.5. Use of Alternative Nicotine Delivery System. Generally, smokers are unaware about THR products used in Pakistan. Firstly, these products are not advertised in the mainstream media, and secondly, they are too expensive and unaffordable for a majority of the smokers. Only $8.6 \%$ respondents claimed having used a THR product in the near past. Of those who had used a THR product, $44.6 \%$ had used it out of curiosity. Since THR products are used in a regulatory vacuum with no medical consultation or assistance, their use remains an individual decision, so much so that $91 \%$ of the vapers did not consult a doctor when they decided to shift to vaping from smoking [13]. Most of the respondents (73.2\%) did not use a THR product after the first use; of these, $26.8 \%$ never planned to use the THR product permanently and $24.4 \%$ said it did not satisfy their need for nicotine. However, $60 \%$ of the respondents said they were willing to use a THR product with the intention of quitting smoking, if it is easily available. The prices of these products nonetheless remain a barrier to wider use. Only $10.9 \%$ of the respondents said they were ready to spend more than Rs. 4000 per month on a THR product (see Table 8). Since almost all vaping products are imported, they are far more expensive than cigarettes. The most expensive duty paid cigarette packet in Pakistan costs a little more than a dollar, while the price of a vaping kit starts from $\$ 24$ and goes up to $\$ 162$. Vaping kits are imported from China and their flavors from the US, UK, and Malaysia [13]. 
TABLE 5: Smokers' attitude.

\begin{tabular}{|c|c|c|c|c|c|c|}
\hline & $\begin{array}{l}\text { Strongly } \\
\text { disagree }\end{array}$ & Disagree & Undecided & Agree & $\begin{array}{c}\text { Strongly } \\
\text { agree }\end{array}$ & $N$ \\
\hline $\begin{array}{l}\text { Do you think cigarette smoking makes young people feel fit in, cool, } \\
\text { etc.? }\end{array}$ & 9.0 & 28.6 & 13.1 & 27.6 & 21.8 & 648 \\
\hline $\begin{array}{l}\text { Do you think cigarettes should be banned at work and in public } \\
\text { places? }\end{array}$ & 1.1 & 5.3 & 3.2 & 35.2 & 55.3 & 648 \\
\hline Do you think young people should stay away from smoking? & 0.5 & 2.3 & 4.6 & 29.9 & 62.7 & 648 \\
\hline $\begin{array}{l}\text { Do you think SHS smoking is harmful for children and other } \\
\text { people? }\end{array}$ & 0.2 & 2.5 & 5.3 & 27.8 & 64.4 & 648 \\
\hline
\end{tabular}

TABle 6: Smokers' attitude.

\begin{tabular}{lcc}
\hline \multicolumn{2}{c}{$\%$} & $N=648$ \\
\hline $\begin{array}{lc}\text { Do you allow people to smoke in your home/car? } \\
\text { Yes }\end{array}$ & 25.9 & 168 \\
No & 74.1 & 480 \\
If not, what is the reason for disallowing? & \\
Cigarette smoke is harmful to others & 70.2 & 409 \\
I am allergic to cigarette smoke & 3.4 & 20 \\
My children/family use my car & 10.5 & 61 \\
Smoking in the car is forbidden & 9.3 & 54 \\
Others & 6.7 & 39 \\
Do you want to quit smoking? & & \\
Yes & 68.2 & 442 \\
No & 31.8 & 206 \\
If not, why have you not quit? & & \\
I am addicted to smoking & 52.9 & 109 \\
Tried but failed to quit & 5.8 & 12 \\
Did quit but relapsed & 1.9 & 4 \\
Most of my friends are smokers & 8.3 & 17 \\
Did not want to as I enjoy smoking & 19.4 & 40 \\
Others & 11.7 & 24 \\
\hline
\end{tabular}

3.6. Smokers' KAP Index. To ascertain the association of smokers' knowledge, attitude, and practices with characteristics, the s-KAP index has been constructed from a factorial analysis using the PCA with selected variables (see Table 9) along with the correlation matrix. In all selected variables, the first factor component is greater than 0.1, except for the two questions getting information about dangers of smoking in the last 30 days and allowing others to smoke in your car. The largest eigenvalues have been used to create an aggregate index score [25]. However, the PCA gives $\mathrm{k}$-main components against $\mathrm{k}$-dimensional data and tries to put as much information in the first components without losing information. The distribution of s-KAP index scores has been presented in Figure 1. The average s-KAP index score was calculated at a median (0.05), with a minimum of -4.02 and a maximum of 5.8 .

A detailed description of the selected s-KAP index variables with the PC1 of the PCA and the mean and standard deviation of each variable is presented in Table 9.

3.7. Association of s-KAP Index. The s-KAP index for age, education, residential area, and quitting of the smokers, as presented in Figures 2(a)-2(d), indicates that smokers' age is the most critical factor for the initiation of combustible smoking. In Pakistan, young children become victims of
TABLE 7: Smokers' practices.

\begin{tabular}{|c|c|c|}
\hline & $\%$ & $N=648$ \\
\hline \multicolumn{3}{|c|}{ How many years have you been smoking cigarettes? } \\
\hline Less than a year & 3.2 & 21 \\
\hline One year & 8.6 & 56 \\
\hline Two years & 13.0 & 84 \\
\hline Three years & 14.5 & 94 \\
\hline More than three years & 60.6 & 393 \\
\hline \multicolumn{3}{|c|}{ Do you currently smoke cigarettes daily or less than daily? } \\
\hline Daily & 75.8 & 491 \\
\hline Less than daily & 24.2 & 157 \\
\hline \multicolumn{3}{|l|}{ How many cigarettes do you smoke daily? } \\
\hline 1 to 5 & 32.3 & 209 \\
\hline 6 to 10 & 23.6 & 153 \\
\hline 11 to 15 & 13.1 & 85 \\
\hline 16 to 20 & 15.7 & 102 \\
\hline More than 20 & 15.3 & 99 \\
\hline \multicolumn{3}{|l|}{ Have you ever tried to quit smoking? } \\
\hline Yes & 48.0 & 311 \\
\hline No & 52.0 & 337 \\
\hline \multicolumn{3}{|c|}{ How many times have you attempted to quit? } \\
\hline Once & 20.3 & 63 \\
\hline Twice & 23.8 & 74 \\
\hline Thrice & 21.9 & 68 \\
\hline More than thrice & 34.1 & 106 \\
\hline \multicolumn{3}{|c|}{ What is the reason behind your failed quit attempt(s)? } \\
\hline Nicotine dependence & 48.3 & 313 \\
\hline Withdrawal symptoms & 7.9 & 51 \\
\hline Living or working with smokers & 15.7 & 102 \\
\hline Stress, depression, anxiety, psychiatric issues & 13.7 & 89 \\
\hline Inability to afford medications or treatment & 1.7 & 11 \\
\hline Others & 12.7 & 82 \\
\hline
\end{tabular}

early smoking without any realization of its side effects and health risks. The comparison of s-KAP index scores between age groups illustrates that the average score for young adults below the age of 20 years was much lower than the national average and the other age groups. The average score for adults aged above 20 years and less than 40 years was significantly higher compared to the above age groups and higher than the national average score, with the exception of the age group of 25 to 30 years. These findings suggest most of the respondents between 15 and 30 years of age have less information regarding combustible smoking, quitting, protecting themselves and children from smoking, smoking-related diseases, and the use of the ANDS/SNDS. A comparison of education and s-KAP index score showed an improvement in the score with level of education and was slightly higher than the 
TABLE 8: Use of alternative nicotine delivery system.

\begin{tabular}{|c|c|c|}
\hline & $\%$ & $N=648$ \\
\hline \multicolumn{3}{|l|}{ Have you used any THR product in the near past? } \\
\hline Yes & 8.6 & 56 \\
\hline No & 91.4 & 592 \\
\hline \multicolumn{3}{|l|}{ If yes, what was the purpose of using the product? } \\
\hline Out of curiosity & 44.6 & 25 \\
\hline Intentionally & 25.0 & 14 \\
\hline To quit smoking & 30.4 & 17 \\
\hline \multicolumn{3}{|c|}{ Did you continue to use the product after the first use? } \\
\hline Yes & 26.8 & 15 \\
\hline No & 73.2 & 41 \\
\hline \multicolumn{3}{|l|}{ If not, what was the reason for discontinuing? } \\
\hline Never planned to use it permanently & 26.8 & 11 \\
\hline Vaping never satisfied my nicotine requirement & 24.4 & 10 \\
\hline Too expensive to afford & 7.3 & 3 \\
\hline Not easily available & 9.8 & 4 \\
\hline It is a hassle to use e-cigarettes & 14.6 & 6 \\
\hline More dangerous than cigarettes & 17.1 & 7 \\
\hline \multicolumn{3}{|c|}{ Are you willing to use safer ANDS to quit smoking, if easily available? } \\
\hline Yes & 60.8 & 394 \\
\hline No & 39.2 & 254 \\
\hline \multicolumn{3}{|c|}{ If yes, how much would you be able to spend on ANDS? } \\
\hline$<$ Rs. 1000 & 27.7 & 109 \\
\hline Rs.1000 up to Rs. 2000 & 24.9 & 98 \\
\hline Rs. 2000 up to Rs. 3000 & 22.1 & 87 \\
\hline Rs. 3000 up to Rs. 4000 & 14.5 & 57 \\
\hline Rs. 4000 and above & 10.9 & 43 \\
\hline
\end{tabular}

TABLE 9: Description of selected s-KAP index variables and factorial analysis.

\begin{tabular}{|c|c|c|c|}
\hline KAP index variables & Comp1 & Mean & Std. Dev. \\
\hline Do you think cigarette smoking can cause cancer(s)? & 0.15 & 0.72 & 0.45 \\
\hline In the last 30 days, did you get any information about the dangers of smoking? & 0.05 & 0.29 & 0.45 \\
\hline Do you think cigarettes should be banned at work and in public places? & 0.27 & 4.38 & 0.86 \\
\hline Do you think young people should stay away from smoking? & 0.22 & 4.52 & 0.73 \\
\hline Do you think SHS smoking is harmful for children and other people? & 0.24 & 4.54 & 0.72 \\
\hline Do you allow people to smoke in your home/car? & -0.21 & 0.26 & 0.44 \\
\hline Do you want to quit smoking? & 0.4 & 0.68 & 0.47 \\
\hline Have you faced any illness/disease because of smoking? & 0.35 & 0.23 & 0.42 \\
\hline Have you ever tried to quit smoking? & 0.38 & 0.48 & 0.5 \\
\hline Did you seek any medical help to quit smoking? & 0.23 & 0.05 & 0.22 \\
\hline Do you know or have you ever heard about THR products? & 0.22 & 0.25 & 0.44 \\
\hline Have you used any THR product in the near past? & 0.28 & 0.09 & 0.28 \\
\hline Did you continue to use the THR product after the first use? & 0.18 & 0.02 & 0.15 \\
\hline Are you willing to use safer ANDS to quit smoking? & 0.34 & 0.61 & 0.49 \\
\hline
\end{tabular}

national average after the intermediate or $12^{\text {th }}$ year of education. This shows education or knowledge related to smoking illness, quitting, and protecting is significantly associated and could be a game changer for controlling the combustible smoking in line with the FCTC guidelines.

Similarly, the s-KAP index association with smokers' residential area showed that upper-middle- and middle-class residential smokers had a higher score relative to rich and poor smokers and a slightly higher score for upper-middleclass smokers than the national average.

In Pakistan, most of the combustible smokers belong to the middle and upper-middle class and use low-cost cigarettes under the family budget constraints. Most of them are willing to quit but are unable to find the supervision or direction for availing the clinical help in this regard. This clearly shows that the government and the tobacco control organizations need to reach out to these smokers who are willing to give up with awareness and necessary clinical help.

Interestingly, the scores of smokers who had ever tried to quit smoking were slightly higher than those of smokers who had never tried to quit. The average score of these smokers was higher than the national average score. Similarly, the score of smokers who smoked on a regular basis was better than that of those who did not smoke on a daily basis. The overall daily smokers' score was higher than the national average. The average score of smokers who used HRPs to 


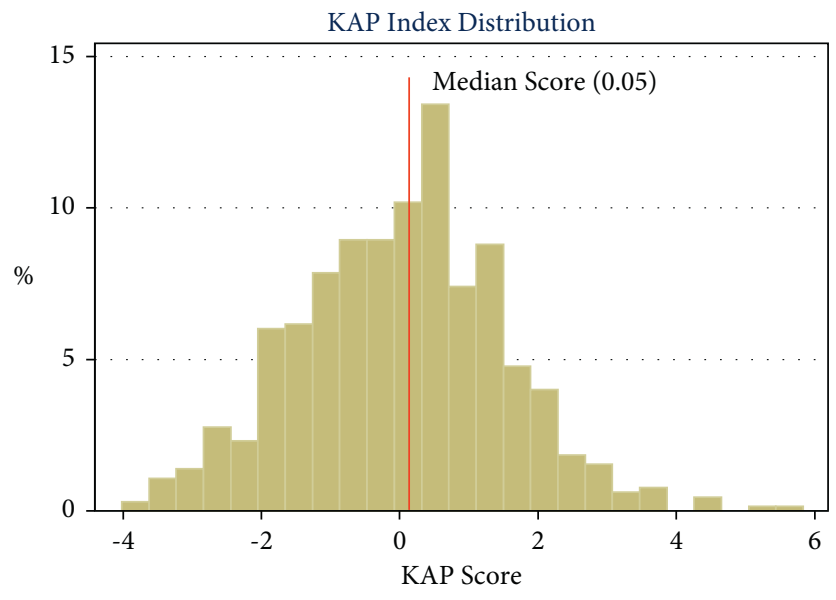

Figure 1: s-KAP index distribution.

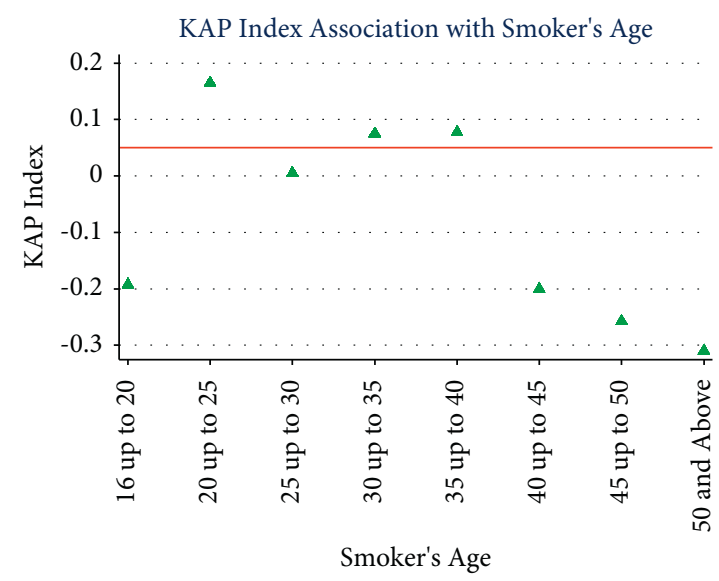

(a)

KAP Index Association with Residential Area

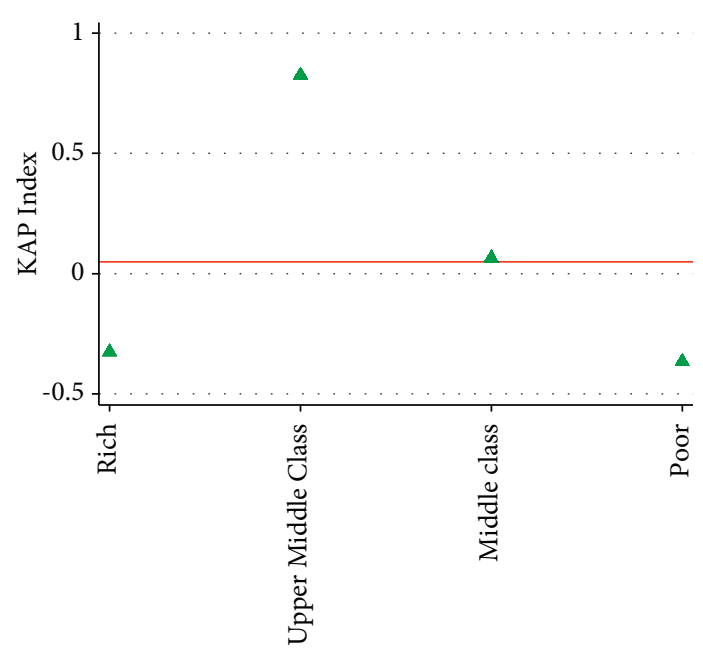

Smoker's Residential Area Classification

(c)

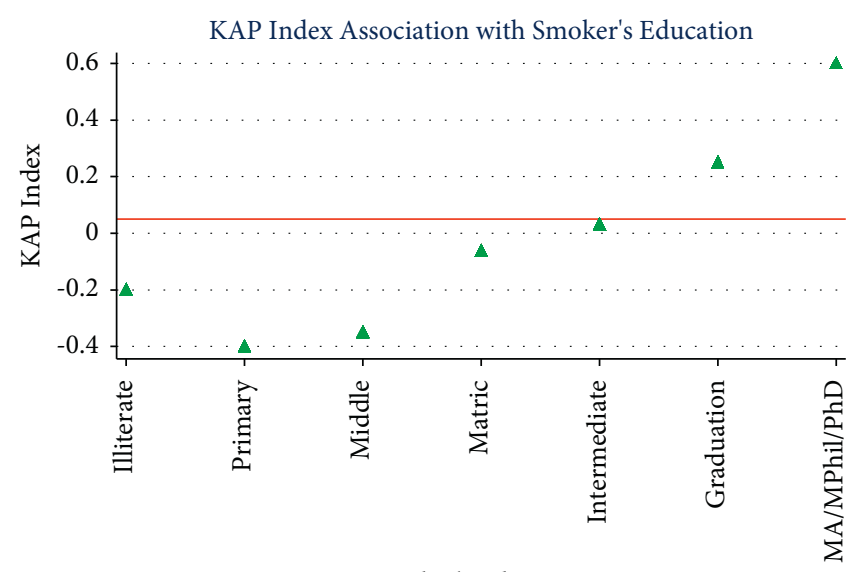

Smoker's Education

(b)

KAP Index Association with Quitting

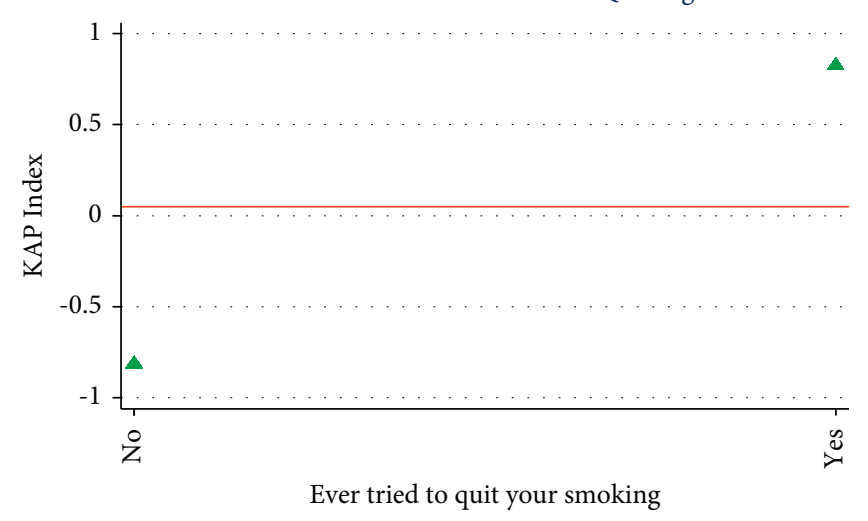

FIGURE 2: KAP index association with age, education, residential area, and attempts to quit smoking. 
stop smoking was higher than that of smokers who did not use HRPs to quit smoking. The average score of HRPs users was slightly higher than the national average (see Figures 3(a) and 3(b)). These behaviors show that smokers who have attempted to quit smoking or used HRPs to quit smoking are better placed than those who have not tried to quit smoking or have not used HRPs.

\section{Discussion}

Using cross-sectional survey data, this study has ascertained the knowledge, attitude, and practice of combustible smokers in 13 districts of Pakistan, and the use of ANDS. Most of the respondents were young and aged between 15 and 30 years. The average age was $28.5 \pm 8.2$ years. Pakistan is the $6^{\text {th }}$ most populated country in the world with a population of 207 million. Almost 64\% of the country's population is under the age of 29 [29]. The prevalence of any form of tobacco use among males and females is $31.8 \%$ and $5.8 \%$, respectively [8], in Pakistan. Smoking among youth is a serious issue in Pakistan. Almost $11 \%$ young people (aged 13-15 years; $13.3 \%$ boys and $6.6 \%$ girls) have used some tobacco product. Young people mostly initiate smoking at an early age; among youth who have ever smoked, $40 \%$ tried their first cigarette smoking before the age of 10 [30].

A predominant $69.8 \%$ of the smokers came from middle-class background, followed by $19.8 \%$ who reported they were poor. These figures contrast with previous studies conducted at the regional level (GATS [8] and Saqib et al. [7]).

After ratifying FCTC, Pakistan has been taking various measures to stem the rising tide of tobacco use. These measures include bans on tobacco advertisements and smoking in public and private places, as well as printing of graphical warnings on cigarette packs, among others [1]. A number of taxes have been imposed on cigarettes and tobacco products [9]. However, smoking cessation seems to be the weakest link in the fight against the tobacco epidemic in Pakistan. The success rate of smoking cessation is less than 3\% [11]. According to the WHO Global Cancer Observatory, in the year 2020, breast, lip oral cavity, lung, esophagus, and colorectum were the top five cancers in Pakistan [31]. In the financial year 2018-19, the federal government withdrew Rs. 28.7 million allocated for the Tobacco Control Cell under the Public Sector Development Program (Dawn. October 6, 2018. Funds for Tobacco Control Cell withdrawn, [available at https://www.dawn.com/news/1437093]). This budgetary cut can be said to have proved detrimental to the cause of public awareness.

According to this study, most of the smokers in Pakistan are keen to quit smoking, know that combustible cigarette smoking is carcinogenic, and even recognize that SHS is harmful for the health of people around them, and their families. These findings are the same as those indicated by Irfan et al. [32] and Shaheen, Oyebode, and Masud [12]. Yet, despite being alive to the dangers of smoking, they are unable to quit. In Pakistan, $72.5 \%$ adults (16.8 million) working indoors are exposed to tobacco smoke at the workplace. Similarly, $86 \%$ adults (49.2 million) are exposed to SHS in restaurants, and $76.2 \%$ in public transport [8]. This shows weak implementation of the smoking ban at the workplace and in public transport. Young people (aged 13-15 years) are also exposed to SHS, $37.8 \%$ in public places and $21 \%$ in their homes [30]. On the average, a smoker in Pakistan consumes 13.6 cigarettes daily [30]. Similarly, every month on average, around 20-25 billion cigarette sticks are legally produced in Pakistan (http://www.pbs.gov.pk/qim).

In Pakistan, peer pressure, anxiety, tobacco dependence, stress, and mood swings have been the most widely observed reasons for not giving up smoking [32]. Additionally, the provision of smoking cessation services is yet to become a priority intervention in the government's tobacco control efforts. The lack of smoking cessation services, which are available to only a few hundred out of the 25 million tobacco users in the country, is a key impediment. Between January 1, 2015, and September 1, 2020, only 2371 smokers had registered with the quit line, and of these, 1439 were referred to the National Institute of Rehabilitation Medicine, which has a smoking cessation clinic. Only 73 smokers succeeded in quitting smoking in the last five years (Maqbool, Shahina. The News, 11 October, 2020. Tobacco control efforts eclipsed by lack of policy [available at https://www.thenews.com. $\mathrm{pk} /$ print/727686-tobacco-control-efforts-eclipsed-by-lackof-policy]). Although Pakistan included NRTs in the Essential Drugs List in 2017, they are expensive and not easily available. It is clear from the study that the intent to quit combustible smoking is present, but the policy and infrastructure necessary for successful quitting is missing. Pakistan needs to concentrate on two fronts: a largescale awareness campaign against the use and harms of combustible smoking and simultaneously providing affordable and accessible smoking services across the country.

Over the last five years, Pakistan has witnessed a steady increase in the number of people using THR products, mainly e-cigarettes [13]. However, their number still remains miniscule compared to the number of tobacco users. Expensive and limited to upscale localities, THR products are being used in a regulatory vacuum. Being legally imported, individuals use them without any medical consultation or advice. Therefore, the shift to THR products from combustible smoking remains an individual decision. Most of the smokers do not know about the availability of THR products. Their main sources of information about these products are friends, and they largely use them out of curiosity.

The high prices of THR products are a major barrier for combustible smokers interested in switching over. This study has found that only $10.9 \%$ of the respondents were ready to spend more than Rs. 4000 per month on a THR product. In Pakistan, the price of a vaping kit starts from $\$ 24$ and goes up to $\$ 162$, primarily because vaping products are imported. The kits are imported from China and their flavors from the US, UK, and Malaysia [13]. Pakistan should look at the use and regulation of safer nicotine products in the UK. Instead of rejecting the SNDS, the country should carefully weigh the options of ensuring how to incorporate the use of SNDS in its 


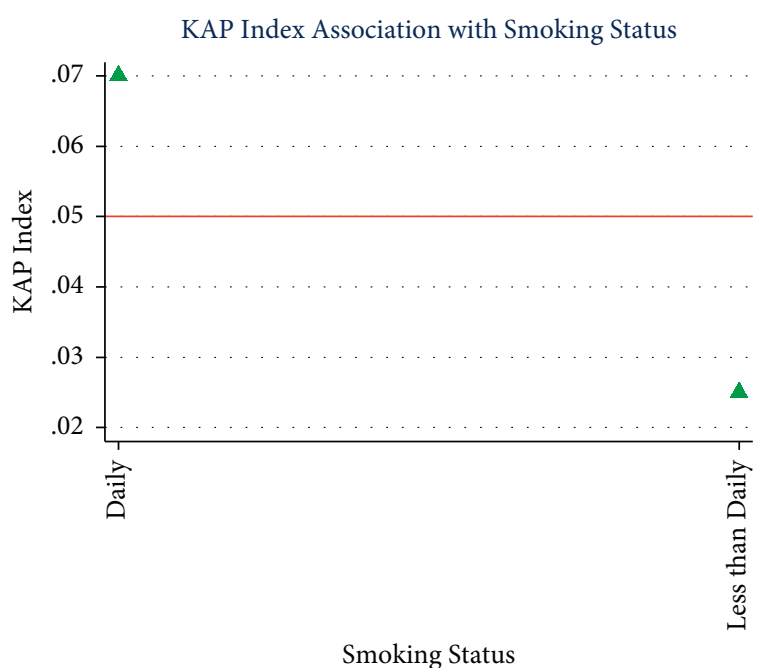

(a)

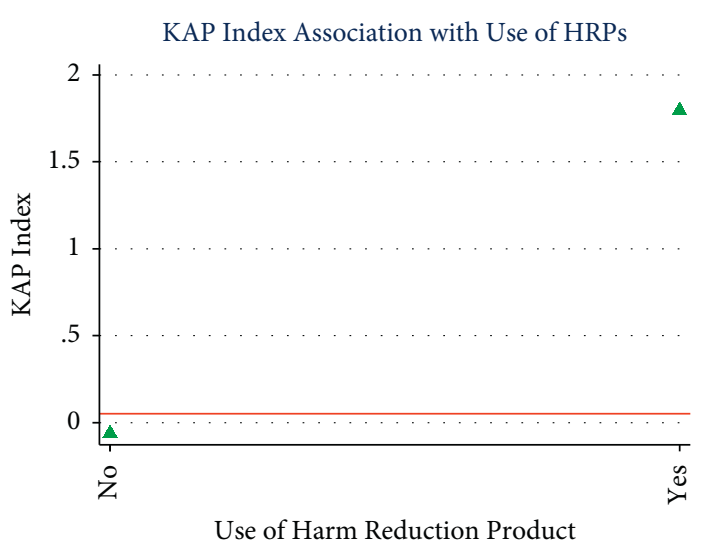

(b)

FIGURE 3: KAP association with smoking status and HRPs.

tobacco control efforts. A sensible approach to regulating SNDS should be adopted. This would mean taking differential approach to taxation vis-à-vis SNDS.

The almost two decades of tobacco control efforts in Pakistan face a critical review. In a country where nearly two-thirds of the population are below 30 years of age, the need to assist adult smokers to quit combustible smoking or switch to THR products can hardly be overemphasized. Simultaneously, efforts should be made to keep the young away from initiating smoking or vaping. For achieving this objective, the government should widen the circle of engagement with stakeholders. The most important stakeholder should be the smokers, who have remained invisible in the efforts for tobacco control. Along with smokers, the government should also engage with the proponents of SNDS and HRP vendors to sensibly regulate their use and ensure that they become affordable for adult smokers who want to give up combustible smoking.

\section{Conclusion}

The component of smoking cessation is almost missing in Pakistan's existing tobacco control efforts and policies. There is a need to establish smoking cessation clinics in hospitals and create buy-in through mass awareness. This assistance should be backed with public advocacy on the negative effects of combustible smoking. Pakistan also needs to develop durable mechanisms to control illicit trade of cigarettes in order to restrict available options of buying cheap, illicit, or smuggled cigarettes. Tobacco law enforcement on smoking at public and private places should be more stringently pursued. There is a need to create an understanding about HRPs, backed by sensible regulation. Currently, the use of HRPs, mainly e-cigarettes, is unregulated and limited to the upper and middle classes. The unregulated use of HRPs in a regulatory vacuum may create space for abuse of HRPs in the form of fake products.
5.1. Limitations and Further Research. This research has been conducted to assess smokers' knowledge and behavior about combustible smoking cessation, prevalence, and risk, and the use of alternative nicotine delivery systems to quit smoking. However, the study was limited by several research constraints during the Covid-19 pandemic. It used 648 respondents' data at the study level representation to assess statistically accurate sample size, using Cochran's sample size formula. Therefore, the sample population is not fully representative at the national level. Interviewing women in Pakistan is difficult due to cultural constraints, especially among tobacco users. Women do smoke in Pakistan but avoid smoking in the public and additionally they would avoid discussing their smoking habit. There, we were unable to find an adult female smoker ready for the interview. The two females in the survey have been included due to incorrect gender code. However, the female sample was calibrated with the male sample. It is a limitation in the study. The study results, based on the data, have been modified. There is a need for national and provincial level research to assess smokers' knowledge and behavior vis-à-vis combustible smoking cessation.

\section{Data Availability}

The data can be obtained from the corresponding author upon request.

\section{Conflicts of Interest}

The authors declare no conflict of interest.

\section{Acknowledgments}

The authors also wish to extend their gratitude to all respondents who agreed to be interviewed. This study was funded with a grant from the Foundation for a Smoke-Free World, a US nonprofit 501(c)(3) private foundation with a mission to end smoking in this generation. The Foundation 
accepts charitable gifts from PMI Global Services Inc. (PMI); under the Foundation's Bylaws and Pledge Agreement with PMI, the Foundation is independent from PMI and the tobacco industry. The contents, selection, and presentation of facts, as well as any opinions expressed herein, are the sole responsibility of the authors and under no circumstances shall be regarded as reflecting the positions of the Foundation for a Smoke-Free World, Inc.

\section{References}

[1] WHO, WHO Report on the Global Tobacco Epidemic, WHO, Geneva, Switzerland, 2019, http://www.who.int/tobacco/ mpower/offer/en/.

[2] A. Navas-Acien, "Global tobacco use: old and new products," Annals of the American Thoracic Society, vol. 15, no. 4, pp. S69-S75, 2018.

[3] M. Ng, M. K. Freeman, T. D. Fleming et al., "Smoking prevalence and cigarette consumption in 187 countries, 1980-2012," JAMA-Journal of the American Medical Association, vol. 311, no. 2, pp. 183-192, 2014.

[4] GSTHR, No Fire, No Smoke: The Global State of Tobacco Harm Reduction 2018, GSTHR, London, UK, 2018, https://www. gsthr.org.

[5] M. Ezzati and A. D. Lopez, "Regional, disease specific patterns of smoking-attributable mortality in 2000," Tobacco Control, vol. 13, no. 4, pp. 388-395, 2004.

[6] C. T. Sreeramareddy, P. M. S. Pradhan, I. A. Mir, and S. Sin, "Smoking and smokeless tobacco use in nine South and Southeast Asian countries: prevalence estimates and social determinants from demographic and health surveys," Population Health Metrics, vol. 12, no. 1, pp. 1-16, 2014.

[7] I. Rafique, M. Arif, N. Saqib, F. Bashir, S. Naz, and S. Naz, "Comparison of tobacco consumption among adults in SAARC countries S-3," Journal of Pakistan Medical Association, vol. 68, no. 5, pp. 2-6, 2018.

[8] GATS, Global Adult Tobacco Survey, Fact Sheet, GATS, Islamabad, Pakistan, 2014.

[9] SPDC, "Role of tobacco in Pakistan's economy," 2018, http:// www.spdc.org.pk/Publication.aspx?mid=22.

[10] J. Khan, "Tobacco epidemic in Pakistan," Journal of Postgraduate Medical Institute, vol. 26, no. 3, pp. 233-236, 2012.

[11] I. A. Chatha, Pre-budget 2018-19 Policy Brief: Govt. Kitty vs Public Health-the Case of Reduction in Prices of Cigarettes in Pakistan, Think-Asia, Islamabad, Pakistan, 2018.

[12] K. Shaheen, O. Oyebode, and H. Masud, "Experiences of young smokers in quitting smoking in twin cities of Pakistan: a phenomenological study," BMC Public Health, vol. 18, no. 466, pp. 1-12, 2018.

[13] ARI, Knowledge, Attitude and Practice Study on Vapers in Pakistan, ARI, Islamabad, Pakistan, 2020.

[14] A. Al-Haqwi, H. Tamim, A. Asery, and A. K. S. Bin, "Knowledge, attitude and practice of tobacco smoking by medical students in Riyadh, Saudi Arabia," Annals of Thoracic Medicine, vol. 5, no. 3, pp. 145-148, 2010.

[15] J. Alqahtani, "Knowledge, attitude and practice of tobacco smoking among health colleges' students at Najran University, Saudi Arabia: a cross-sectional descriptive study," Journal of Health Specialties, vol. 5, no. 1, pp. 35-41, 2017.

[16] M. S. Chisolm, E. P. Brigham, S. J. Lookatch, M. Tuten, E. C. Strain, and H. E. Jones, "Cigarette smoking knowledge, attitudes, and practices of patients and staff at a perinatal substance abuse treatment center," Journal of Substance Abuse Treatment, vol. 39, no. 3, pp. 298-305, 2010.

[17] A. Jawaid, A. M. Zafar, T. U. Rehman et al., "Knowledge, attitudes and practice of university students regarding waterpipe smoking in Pakistan," International Journal of Tuberculosis \& Lung Disease: the Official Journal of the International Union Against Tuberculosis and Lung Disease, vol. 12, no. 9, pp. 1077-1084, 2008.

[18] M. I. Nurmansyah, Y. Umniyatun, M. Jannah, A. T. Syiroj, and D. N. Hidayat, "Knowledge, attitude and practice of cigarette smoking among senior secondary school students in Depok, Indonesia Abstract," International Journal of Adolescent Medicine and Health, vol. 33, no. 2, 2019.

[19] M. Smith and T. Umenai, "Knowledge, attitude and practice of smoking among university students of allied health sciences in Japan," Asia-Pacific Journal of Public Health, vol. 12, no. 17, pp. 17-21, 2000.

[20] R. T. Hamner and S. H. Stumpf, "Survey of smoking knowledge, attitudes and practice in school children in Honduras," Family Practice, vol. 18, no. 6, pp. 627-628, 2001.

[21] Y.-S. Lin, D.-M. Wu, H.-R. Lai, Z.-P. Shi, and N.-F. Chu, "Influence of knowledge and attitudes on smoking habits among young military conscripts in Taiwan," Journal of the Chinese Medical Association, vol. 73, no. 8, pp. 411-418, 2010.

[22] M. R. Torabi, J. Yang, and J. Li, "Comparison of tobacco use knowledge, attitude and practice among college students in China and the United States," Health Promotion International, vol. 17, no. 3, pp. 247-253, 2002.

[23] I. U. H. Padda and A. Hameed, "Estimating multidimensional poverty levels in rural Pakistan: a contribution to sustainable development policies," Journal of Cleaner Production, vol. 197, no. 1, pp. 435-442, 2018.

[24] S. O. Rutstein and K. Johnson, “The DHS wealth index," 2004, http://library1.nida.ac.th/termpaper6/sd/2554/19755.pdf.

[25] S. Vyas and L. Kumaranayake, "Constructing socio-economic status indices: how to use principal components analysis," Health Policy and Planning, vol. 21, no. 6, pp. 459-468, 2006.

[26] I. T. Jolliffe, "Principal components analysis," in Springer Series in Statistics, Springer, Berlin, Germany, 2nd edition, 2002.

[27] S. Ali, I. S. Chaudhry, and F. Farooq, Human Capital Formation and Economic Growth in Pakistan, vol. 32, no. 1, pp. 229-240, 2012.

[28] F. Khaliq and W. Ahmad, State of health sector in Pakistan, 2018.

[29] GoP, Pakistan Economic Survey 2018-19, GoP, Islamabad, Pakistan, 2019.

[30] WHO, Global Youth Tobacco Survey: Country Fact Sheets, WHO, Geneva, Switzerland, 2014.

[31] WHO, The Global Cancer Obervatory: Pakistan Fact Sheet, WHO, Geneva, Switzerland, 2020.

[32] M. Irfan, A. S. Haque, H. Shahzad, Z. A. Samani, S. Awan, and J. A. Khan, "Reasons for failure to quit: a cross-sectional survey of tobacco use in major cities in Pakistan," International Journal of Tuberculosis \& Lung Disease, vol. 20, no. 5, pp. 673-678, 2016. 